who operate reactors, for example, would agree that a continuous and incorruptible record should be kept of, say, neutron flux or some other physical quantity sensitive to the movement of nuclear material within them. The safeguards system now in use, devised merely to account for quantities of fissile material in the input to and the output from a reactor, does not require the collection of such data - which would in some places be regarded as an infringement of national sovereignty. It is not too soon to plan for a return of this provision at the next meeting of the signatories of the treaty three years from now.

Further ahead, there is a strong case for planning for a much more radical simplification of the safeguards system. Even as things are, governments with nuclear installations on their territory will, if they are prudent, take steps to make sure that fissile material is not spirited away. These domestic interests thus coincide with those of the international safeguards inspectorate, but the work is duplicated. The ideal, then, would be that selfpolicing should be done in such a way that it could be unambiguously and internationally verified. (Some concessions to this notion are already made within the Euratom system, which has its own set of safeguards.) The sooner this goal is recognized, the more likely it is to be attained. And that, in the long run, will be the best assurance that this important instrument in the nonproliferation system remains intact.

\section{Problem not for now}

\section{Is it too soon to be worrying about who should operate the shuttle system?}

If this week's space shuttle, diverted by the aftermath of heavy rain from California to New Mexico, returns successfully, the chance that it will become a white elephant will substantially have diminished. The first two flights have shown that the machine will function as intended. This time there should be information bearing on its potential usefulness. But it will be a long time before anybody will known that the shuttle will do the job for which it has been built - to put large satellites cheaply into orbit. The immediate need is to reduce the intervals between successive flights of the one machine in service - an interval artificially lengthened by the need to return it from its landing site to its launching pad in Florida but also by the need to replace whatever ceramic tiles have fallen off in flight. The plan is that the next flight but one should take off from and land in Florida, but only when there are four machines in service will it be possible to tell whether the turn-round time is really as short as planned.

So why is the United States government already in a tizzy trying to decide within what legal framework the shuttle should be operated in the closing years of this decade? It is not even as if the problem is all that novel. The development of telecommunications satellites in the 1960s is an obvious precedent. Then, as with the shuttle, there were three kinds of customers in sight - the US Department of Defense, potential users of communications satellites in the United States and customers from elsewhere, principally the international consortium of communications authorities called Intelsat. The largely successful solution was to leave the launching of military satellites to the Pentagon and to set up the corporation called Comsat as an organization independent of the government for launching and managing communications satellites.

Operating the shuttle commercially will be more complicated only in two respects. It may turn out to be uneconomic to have separate spacecraft for civil and military launchings, while, for a time at least, whoever owns the first four spacecraft will enjoy a monopoly of some kind. But there is no reason why a corporation along the lines of Comsat should not occasionally work for the military, and no reason why the temptation to make outrageous profits should not be restrained by a modicum of regulation. These difficulties will be clarified only several years from now. In the meantime, it might be thought, the US government has more urgent problems crying out for its attention.

\section{Europe in the doldrums}

Could science and technology help the EEC to a second twenty-five years?

What is to become of the European Community, which will be celebrating its twenty-fifth anniversary this week? On recent form, member governments will use what energy they can spare for the Community on now-familiar disputes about the prices that farmers should be paid for various foodstuffs or the shares to which they are entitled from this and that central fund. In their defence, governments will say that in the middle of a recession and with more than 10 million people unemployed in Europe, this cannot be the time for pausing in the pursuit of self-interest. They will also rightly say that a great deal has been accomplished in a quarter of a century. There is a customs union which works reasonably well. The Community has been enlarged (from six to ten, but Greece is shaky). And there is a sense that Europe is culturally more of a piece than it was. The snag is that the benefits are intangible, so that it is the public quarrels that stick in people's minds.

That things should have come to such a pass is easily understood. The treaty signed in Rome on 25 March 1957 was necessarily a blend of idealism and practical politics. The earlier collapse of the plan to set up a European Defence Force had warned the negotiators that even the tiniest infringement of national sovereignty would have to be made explicit and agreed in advance. Although there has recently been some talk of concerted action on defence the European Community is unlikely to be chosen as the vehicle.

The tentativeness of the past quarter of a century means that even now the Community does not enjoy economic cohesion. While private companies are required to compete with each other freely, governments can and do bias their purchases in favour of their own national suppliers, thus denying all members of the Community the benefits of scale and of an economic division of labour in some of the most important fields of technology. There was a minor sensation when British Telecom ordered new exchange equipment from a non-British corporation, but nobody appears seriously to have suggested that the British Central Electricity Generating Board should order the pressurized water reactor it wants to build from say Framatome (see page 299). Yet the European Commission in Brussels is wringing its hands over what used to be called the "technology gap" and seeking some way of strengthening the industries that its members have themselves weakened by their purchasing policies. Would it not be more productive to work out some set of inducements for persuading the member governments that they must give up their technological chauvinism?

Much the same question should soon be asked about the support of Community governments for research. Over the past quarter of a century spending by the European centre on research has if anything been set back. At the outset there was Euratom, but now there is merely the Joint European Torus and a miscellaneous programme of research at the old Euratom. laboratory in Italy. Otherwise, governments deal independently with their spending on research, making separate decisions about their membership of international organizations or their spending in their domestic laboratories.

Up to a point, all this is justifiable. Governments responsible for universities also have to equip them for carrying out research, but even here there is scope for planning on a European basis complementarity between the centres of excellence that different governments support. Elsewhere, it is shocking that so little has been done to coordinate research on problems or fields of common interest. Should not, for example, something be done to concert the very considerable efforts in agricultural research, not so as to save money but in the hope of becoming more effective? The stock answer, that coordination works only inefficiently, is another way of saying that Europe is better balkanized. It would be better to devise machinery that made efficient collaboration possible. 